\title{
Development and Evaluation of Compact Robot Imitating a Hermit Crab for Inspecting the Outer Surface of Pipes
}

\author{
Naoto Imajo, Yogo Takada, and Mikiji Kashinoki \\ Osaka City University, 3-3-138 Sugimoto, Sumiyoshi-ku, Osaka-shi, Osaka 558-8585, Japan \\ Correspondence should be addressed to Yogo Takada; takada@mech.eng.osaka-cu.ac.jp
}

Received 14 January 2015; Revised 20 April 2015; Accepted 13 May 2015

Academic Editor: Liwei Shi

Copyright (C) 2015 Naoto Imajo et al. This is an open access article distributed under the Creative Commons Attribution License, which permits unrestricted use, distribution, and reproduction in any medium, provided the original work is properly cited.

\begin{abstract}
Terrestrial hermit crabs which are a type of hermit crabs live on land, whereas typical hermit crabs inhabit the sea. They have an ability of climbing a tree vertically. Their claws allow them to hang on the tree. In this study, an outer-pipe inspection robot was developed. Its locomotion mechanism was developed in imitation of the terrestrial hermit crab's claws. It is equipped with two rimless wheels. Each of the spokes is tipped with a neodymium magnet, which allows the robot to remain attached to even a vertical steel pipe. Moreover, the robot has a mechanism for adjusting the camber angle of the right and left wheels, allowing it to tightly grip pipes with different diameters. Experiments were conducted to check the performance of the robot using steel pipes with different diameters, placed horizontally, vertically, or obliquely. The robot attempted to move a certain distance along a pipe, and its success rate was measured. It was found that the robot could successfully travel along pipes with vertical orientations, although it sometimes fell from oblique or horizontal pipes. The most likely reason for this is identified and discussed. Certain results were obtained in laboratory. Further experiments in actual environment are required.
\end{abstract}

\section{Introduction}

There are many aging petrochemical plants, which makes maintenance an important issue. Such plants contain a large number of steel pipes running horizontally, vertically, and obliquely, and inspecting them is both costly and timeconsuming. It can also be a difficult process in areas where pipes are densely packed. For these reasons, there is a strong demand for practical pipe inspection robots to aid in this task.

Pipe inspection robots are divided into two types. One type is an inner-pipe inspection robot which moves inside pipe [1-4]. Another type is outer-pipe inspection robot which moves outside pipe. In this study, we focused on the latter because it is expected that the pipe inspection robot would be applied to other structure inspection such as a bridge cable as well as pipe inspection. Several outer-pipe and bridge cable inspection robots have already been developed, and they are capable of moving along pipes and the cables. However, one type is incapable of overcoming obstacles on the surface of the pipe and the cable [5-7]. Another has a specialized mechanism for overcoming obstacles, but the mechanism is too bulky to allow them to be used with narrow pipes [8]. There is therefore a need for an outer-pipe inspection robot that can move along such narrow pipes and overcome obstacles. If it is not limited to the inspection robot for pipes, permanent magnetic adhesion mechanism is one of the methods for moving on surface of the structure $[9,10]$.

Terrestrial hermit crabs live on land, whereas typical hermit crabs inhabit the sea. They have an ability of climbing a tree vertically. Their claws allow them to hang on the tree. In imitation of the terrestrial hermit crab's locomotion mechanism, we have previously developed a four-wheel-drive bridge inspection robot with rimless wheels [11]. The terrestrial hermit crabs have some legs. The pair of front legs has large claws. The hermit crabs alternately hang the two claws on tree surface and climb up the tree. The climbing motion of the hermit crabs inspired us to develop the bridge inspection robot having the rimless wheels. The spoke of the rimless wheels was constructed to mimic the hermit crab's claws. Each of the spokes is tipped with a permanent magnet, allowing the robot to move over flat steel surfaces, including walls and ceilings. When the robot climbs up steel wall with rolling rimless wheel, each of the spokes attaches to the wall in 
sequence. The sequence of motion is similar to the climbing motion of the hermit crab using claws. The robot is also capable of overcoming obstacles along its path, due to its rimless wheels. However, it cannot be used on pipes because it does not have the ability to remain attached to cylindrical surfaces, except if the diameter is considerably larger than the robot itself. Nevertheless, the rimless wheel concept is considered to be promising for a pipe-climbing robot also.

In the present study, a prototype two-wheeled outer-pipe inspection robot was developed, which can move vertically along narrow pipes or wires. It is equipped with the same rimless wheels imitating the hermit crab's claws. The performance of the robot was evaluated using pipes with different diameters and orientations.

\section{General Description of Outer-Pipe Inspection Robot}

2.1. Requirements for Pipe-Inspection Robot. The following requirements are considered essential for a robot that can perform pipe inspections.

(1) The robot should be capable of moving along the outer surface of pipes, regardless of their diameter or orientation.

(2) It should be able to overcome obstacles on the surface of a pipe and negotiate bends.

(3) It should be capable of remaining attached to a pipe for extended periods of time in order to perform an inspection. It should therefore be light and use little electric power. It should have a large capacity battery and consume less power when it is motionless on the pipe.

(4) It should be capable of supporting the weight of sensors for detecting corrosion or cracks.

2.2. Conceptual Design of Outer-Pipe Inspection Robot. In the present study, a compact two-wheel-drive design was chosen, since this was considered to be capable of satisfying the above requirements. As shown in the schematic illustration in Figure 1, the robot uses right and left rimless, spoked wheels. If there are small obstacles on the path, the robot can stride them by spokes. Each of the spokes is tipped with a neodymium permanent magnet, which allows the robot to remain permanently attached to a steel pipe. One common problem with such two-wheeled robots is that their body becomes rotated due to the reaction torque from the motor when the wheels are turned, preventing them from moving straight. To solve this issue, the robot in the present study is equipped with a rear wheel to eliminate pitching motion. Figure 2 schematically shows the robot attached to the outer surface of a pipe. It has a link mechanism for adjusting the camber angle of its wheels so that it can adapt to different pipe diameters. Initial attempts by the robot to move on a pipe were unsuccessful. One of the wheels did move and produced a yawing motion, causing the robot to fall from the pipe. To

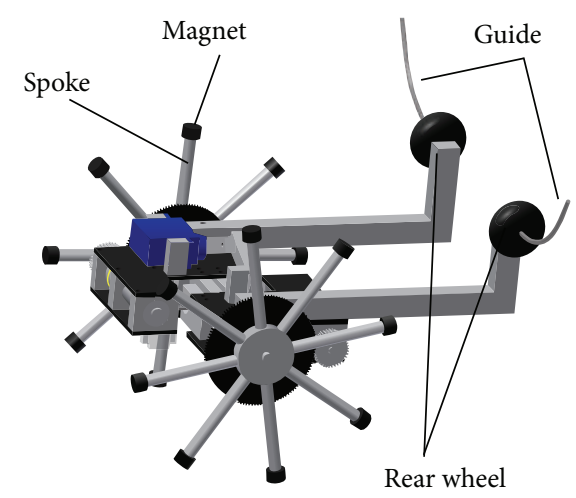

FIGURE 1: Conceptual design of outer-pipe inspection robot.

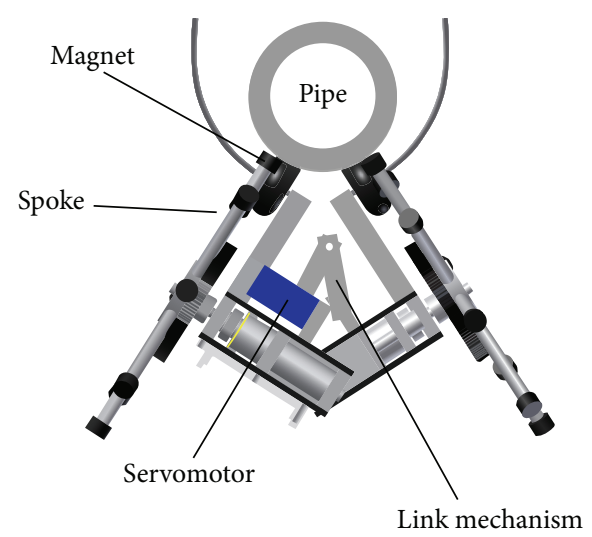

FIGURE 2: Robot attached to pipe.

overcome the problem of yawing, the robot is equipped with guides to hold the pipe as shown in Figure 1.

2.3. Magnetic Force between Robot and Steel Pipe. As illustrated in Figure 3, each of the rimless wheels has eight spokes, on the end of which is a permanent magnet with a length of $5 \mathrm{~mm}$ and a diameter of $8 \mathrm{~mm}$. In order to ensure that the robot can remain attached to a pipe regardless of the orientation of either the robot or the pipe, the attractive magnetic force between the two must exceed the gravitational force acting on the robot.

Figure 4 illustrates the magnetic force $F_{m}$ acting between one of the wheel spokes and a flat steel surface. It varies as a function of the distance $L$ between the permanent magnet and the steel surface. Figure 5 shows the dependence of $F_{m}$ on $L$, calculated using the computation tool for magnetic-flux density and absorption force from NeoMag Co., Ltd.

Since it is difficult to perform a theoretical analysis of the magnetic force when $L$ is too small, the $F_{m}$ value of $14.7 \mathrm{~N}$ for $L=0.4 \mathrm{~mm}$ is used for all distances $L<0.4 \mathrm{~mm}$. When the spoke is not vertical but instead makes an angle $\alpha$ to the vertical axis, the distance between the magnet and the steel surface is not uniform, as shown in Figure 6, so that the magnetic force varies with $\alpha$. One of the authors derives the following 


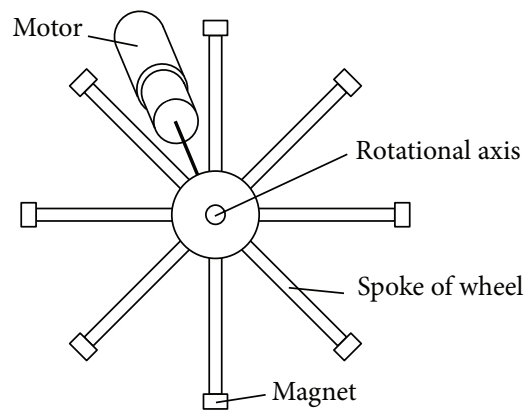

FIGURE 3: Schematic of rimless wheel and magnets.

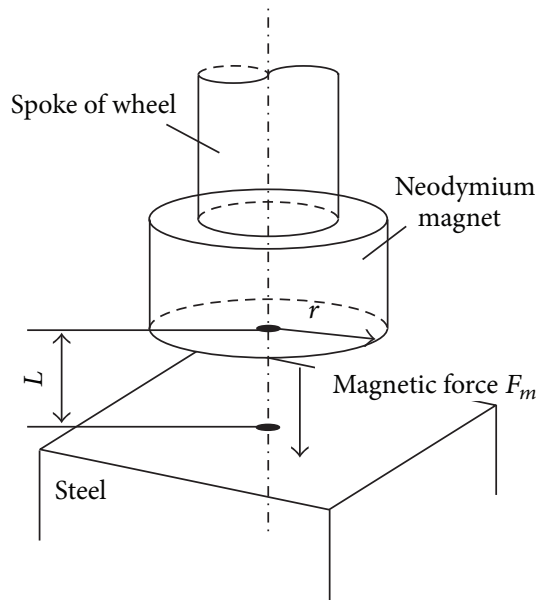

Figure 4: Magnetic force between spoke and steel surface.

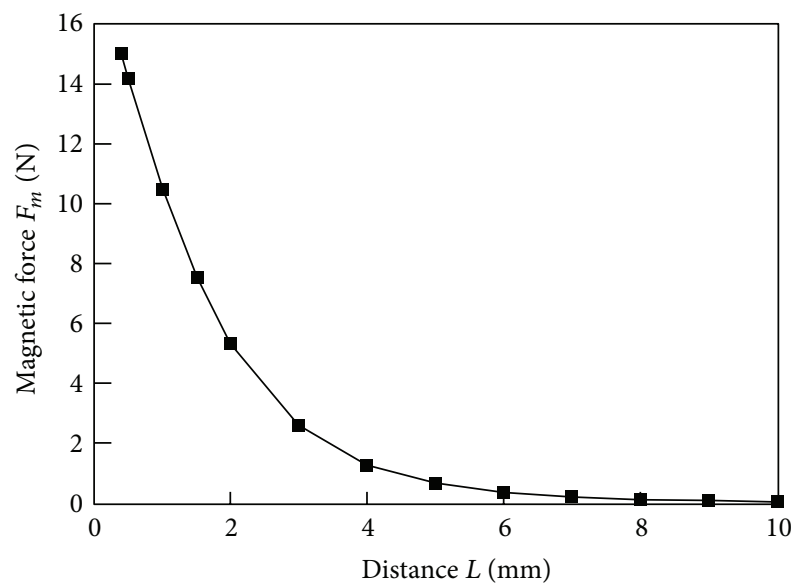

FIgURE 5: Dependence of magnetic force on distance.

equation of the magnetic force [11]. The magnetic force is given by

$$
\begin{aligned}
F_{m} & =\int_{0}^{2 r} \frac{2 \sqrt{2 r x-x^{2}}}{\pi r^{2}(b x-L)^{2}} d x \\
b & =\sin \alpha,
\end{aligned}
$$

where $r$ is the radius of the magnet. Figure 7 shows the relationship between $F_{m}$ and $\alpha$. The wheel has eight spokes.

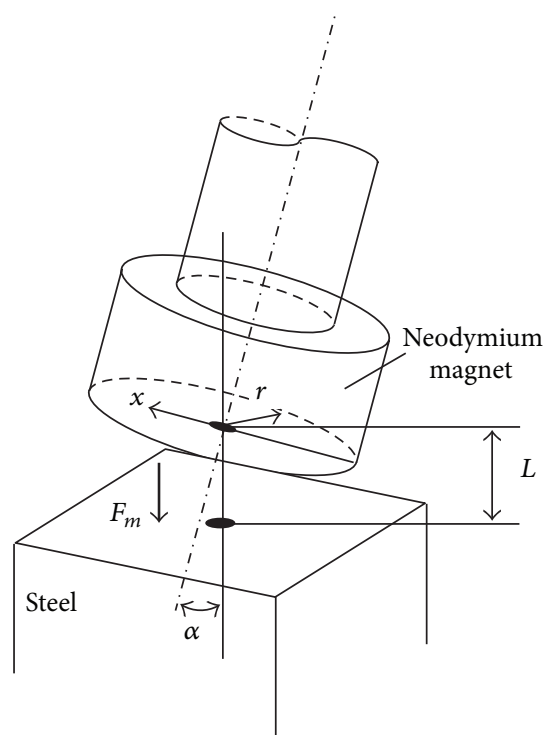

FIGURE 6: Magnetic force for tilted spoke.

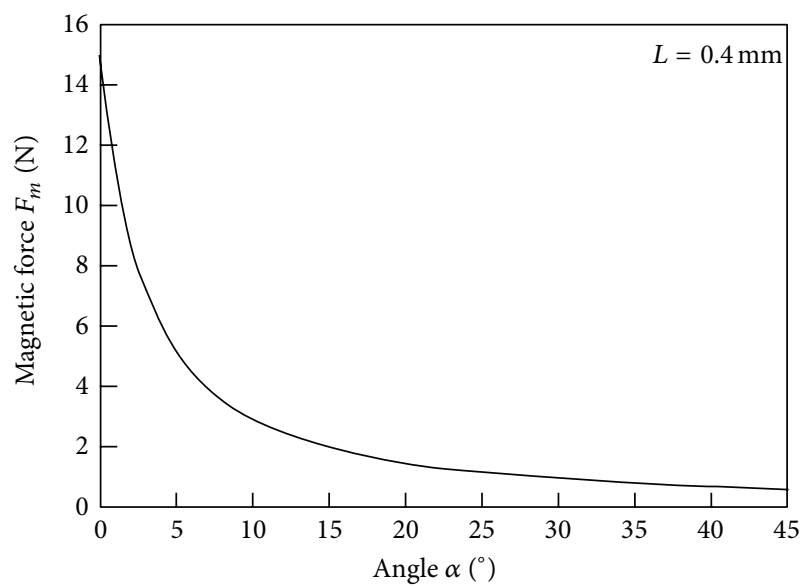

Figure 7: Relationship between magnetic force and tilt angle.

Therefore, when the wheel is rolling on a steel pipe, its spoke is detached from the pipe at $\alpha=22.5^{\circ}$. When $\alpha=22.5^{\circ}, F_{m} \cong$ $1.2 \mathrm{~N}$, which is about $8 \%$ of the value for $\alpha=0^{\circ}$. Therefore, the magnet can be detached from the steel pipe by a much smaller force. Based on these results, a prototype robot was constructed, as described in the following section.

\section{Construction of Prototype Robot}

Figure 8 shows a schematic diagram of the prototype robot. It weighs $380 \mathrm{~g}$ and is $180 \mathrm{~mm}$ in length, $124 \mathrm{~mm}$ in width, and $110 \mathrm{~mm}$ in height. In order to minimize the weight of the robot, carbon fiber-reinforced plastic and duralumin are used to construct the frame. The permanent magnets are coated with rubber cement to prevent slipping on the steel pipe. The robot is driven using DC reduction motors equipped with a gearbox with planetary gears. These motors are light $(15 \mathrm{~g})$ and can produce a high torque. To evaluate its performance, it 


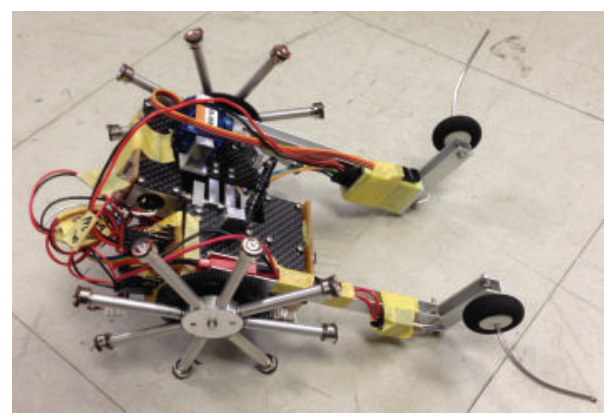

FIGURE 8: Prototype robot.

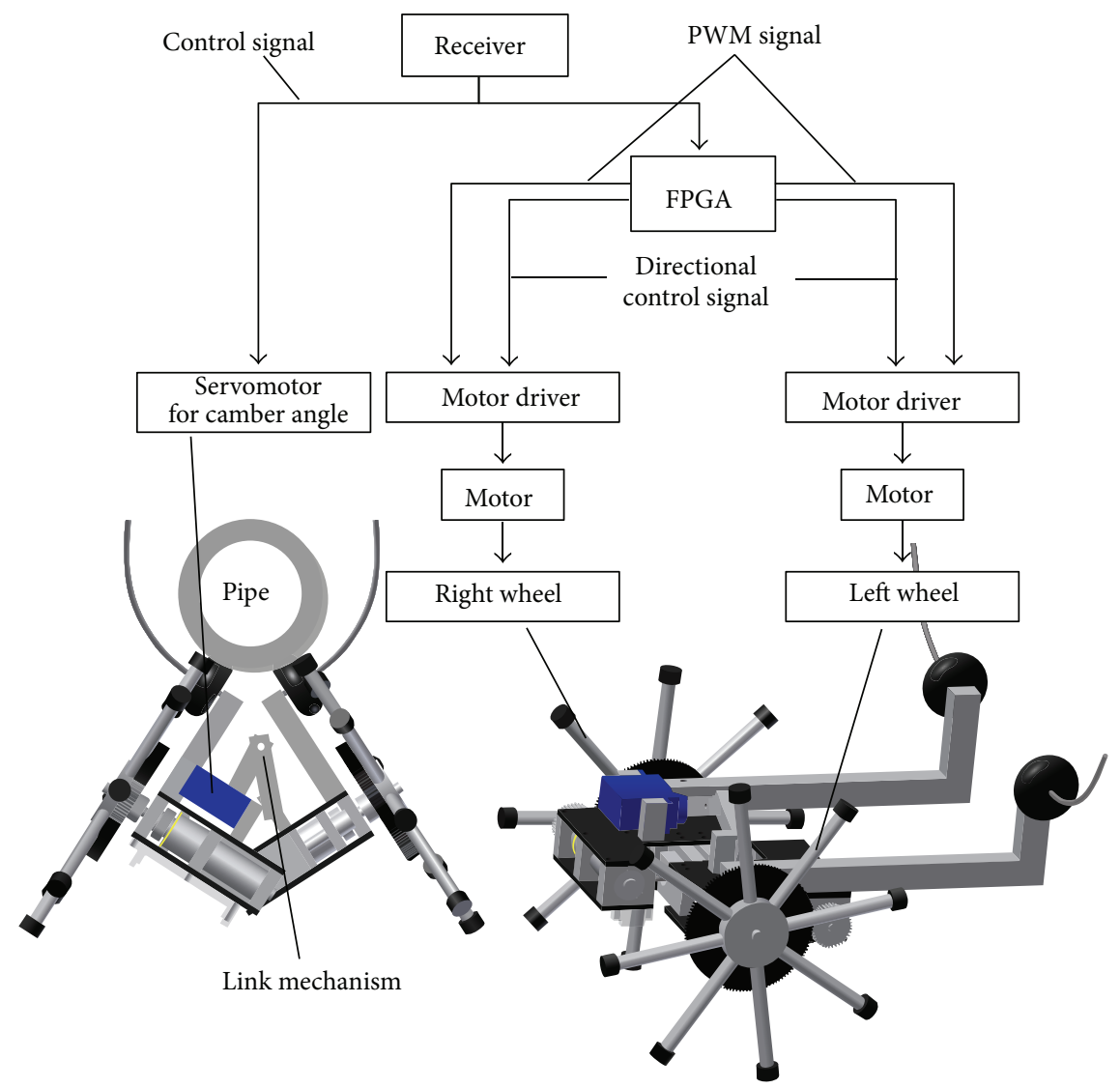

FIGURE 9: Signal flow for robot control.

was gradually subjected to a load torque for an applied voltage of 1.5 or $3.0 \mathrm{~V}$. When the motor stopped rotating, the measured torque was $0.0908 \mathrm{Nm}$ at $1.5 \mathrm{~V}$ and $0.181 \mathrm{Nm}$ at $3.0 \mathrm{~V}$ [12]. Thus, the motor torque is roughly proportional to the input voltage. For an applied voltage of $7.4 \mathrm{~V}$, the motor torque can therefore be calculated to be $0.446 \mathrm{Nm}$. Moreover, two reducing gears were attached to the robot, with 37 and 116 gear teeth, giving a gear ratio of 3.14. If the transmission efficiency of the reducing gears is 0.9 , the torque of the robot is then $0.446 \times 3.14 \times 0.90=1.26 \mathrm{Nm}$. Figure 9 shows the signal flow used to control the robot. The signals are transmitted (T6J, Futaba Co., Ltd.) wirelessly to a receiver (R2106GF, Futaba Co., Ltd.) on the robot. A field-programmable gate array
(FPGA; XC6SLX9-2TQG144C, Xilinx Co., Ltd.) is used to process the PWM signals from the receiver and issues signals including directional controls to the motor drivers, which cause the motors to rotate. The robot is also equipped with a servomotor for adjusting the camber angle of the wheels. The guides are made of curved lengths of wire. Two small wheels are attached to the rear of the robot for repressing pitching motion. Those wheels do not deface the surface of the pipe.

\section{Performance of Prototype Robot}

Since an actual outer-pipe inspection robot will be expected to carry sensors and other devices, the maximum movable 

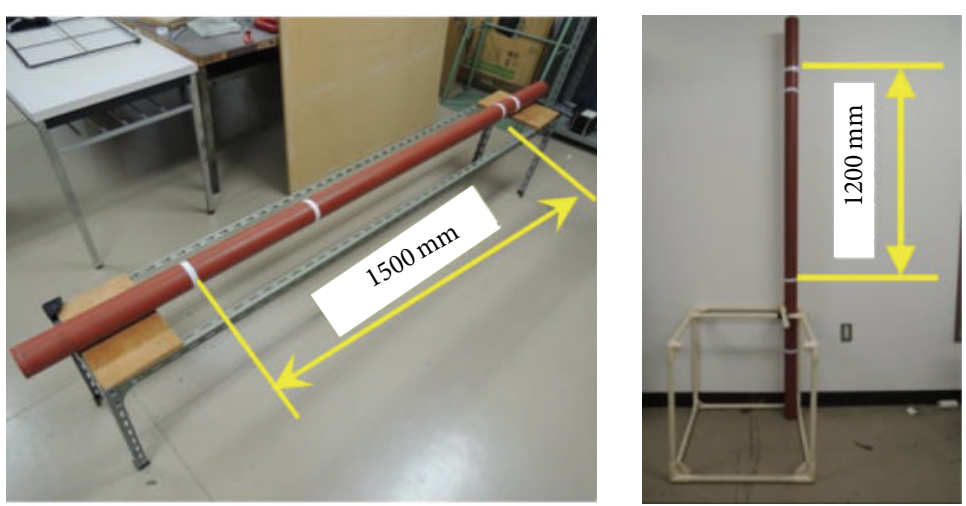

FIgURE 10: Experimental setup for testing robot movement.

TABLE 1: Movable load during vertical movement.

\begin{tabular}{ll}
\hline Maximum movable load (without slip) & $155 \mathrm{~g}$ \\
Maximum movable load (with slip) & $245 \mathrm{~g}$ \\
\hline
\end{tabular}

TABLE 2: Electric power consumption.

\begin{tabular}{ll}
\hline Climbing with $0 \mathrm{~g}$ load & $4.56 \mathrm{~W}$ \\
Climbing with $155 \mathrm{~g}$ load & $6.59 \mathrm{~W}$ \\
\hline
\end{tabular}

load during vertical movement on the wall was first determined, and the results are shown in Table 1 . The robot will be expected to move vertically on the wall without slip. The movable loads without slip and with slip are measured. Table 2 shows the electric power consumption of the robot for different loads.

To evaluate the performance of the robot, experiments were carried out using steel pipes with different diameters. Several experiments were conducted with the outer-pipe inspection robot. We prepared SGP pipes with various diameters. The SGP is a carbon-steel pipe used for transportation of gas, oil, and other materials in Japan. The nominal external diameters of the steel pipes were $15 \mathrm{~A}(21.7 \mathrm{~mm}), 50 \mathrm{~A}$ $(60.5 \mathrm{~mm}), 65 \mathrm{~A}(76.3 \mathrm{~mm})$, and $90 \mathrm{~A}(101.6 \mathrm{~mm})$. The pipes were coated with corrosion-resistant paint. Figure 10 shows the experimental setup used for testing the ability of the robot to travel a fixed distance. This shows the cases only for horizontal and vertical movement, but the full range of tilt angles was $0^{\circ}$ (horizontal), $30^{\circ}, 45^{\circ}, 60^{\circ}$, and $90^{\circ}$ (vertical). For the horizontal case, the required travelling distance for the robot was $1500 \mathrm{~mm}$, and for all other angles it was $1200 \mathrm{~mm}$. Experiments were conducted twenty times by each route. Figure 11 shows the relationship between the movement speed and the inclination angle. Figures 12 and 13 show example photographs of the robot undergoing vertical and horizontal movement, respectively.

Table 3 shows the success rates for the different inclination angles and pipe diameters. As can be seen, the robot failed to complete the entire distance for the case of the pipe with a diameter of $21.7 \mathrm{~mm}$, regardless of the inclination angle. This was because for this narrow pipe, both of the rimless wheels could not make contact with the pipe at the same time.
TABLE 3: Success rate for movement on the pipe.

\begin{tabular}{|c|c|c|c|c|}
\hline \multirow{3}{*}{$\begin{array}{l}\text { Tilt angle of } \\
\text { steel pipes }\end{array}$} & \multicolumn{4}{|c|}{ Success rate } \\
\hline & \multicolumn{4}{|c|}{ External diameter } \\
\hline & $21.7 \mathrm{~mm}$ & $60.5 \mathrm{~mm}$ & $76.3 \mathrm{~mm}$ & $101.6 \mathrm{~mm}$ \\
\hline $0^{\circ}$ & \multirow{5}{*}{$\begin{array}{l}\text { Cannot run } \\
\text { the whole } \\
\text { distance }\end{array}$} & $65 \%$ & $95 \%$ & $90 \%$ \\
\hline $30^{\circ}$ & & $95 \%$ & $100 \%$ & $100 \%$ \\
\hline $45^{\circ}$ & & $100 \%$ & $85 \%$ & $95 \%$ \\
\hline $60^{\circ}$ & & $100 \%$ & $100 \%$ & $95 \%$ \\
\hline $90^{\circ}$ & & $100 \%$ & $100 \%$ & $100 \%$ \\
\hline
\end{tabular}

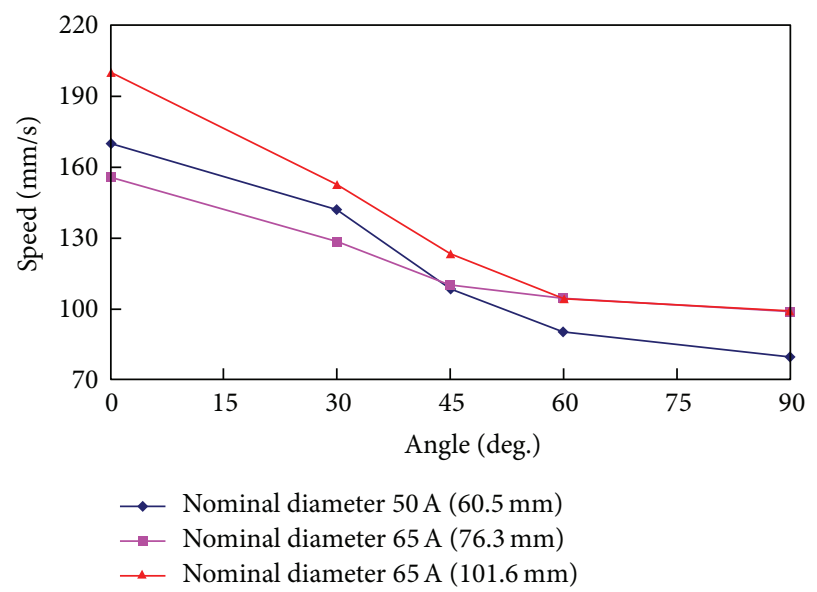

FIGURE 11: Relationship between movement speed and inclination angle of steel pipe.

Although further investigation is needed, it is likely that if the spokes are made longer, the robot would be able to travel even on such a narrow pipe. For other pipe diameters, the success rate was above $85 \%$, except for the case of the $60.5 \mathrm{~mm}$ diameter horizontal pipe, where the success rate was $65 \%$. Normally, it would be thought that it would be more difficult for the robot to travel at an inclined angle rather than horizontally, but this was not the case in the present study. Therefore, we carefully observed the behavior of the robot when travelling horizontally on the $60.5 \mathrm{~mm}$ diameter pipe. 


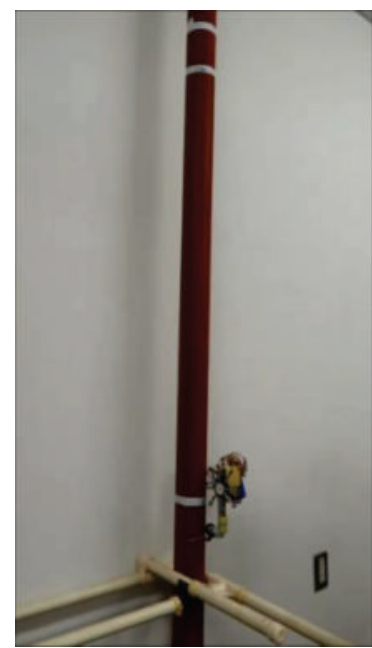

$0.0 \mathrm{~s}$

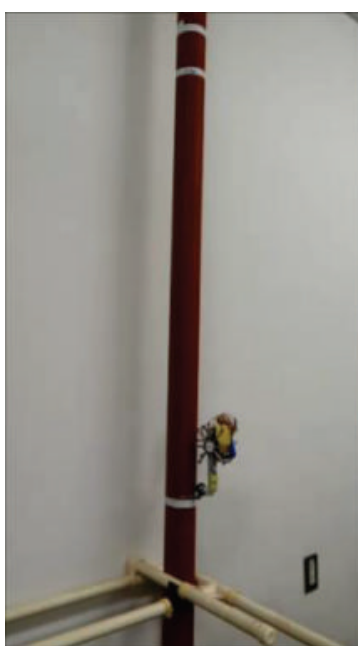

$2.0 \mathrm{~s}$

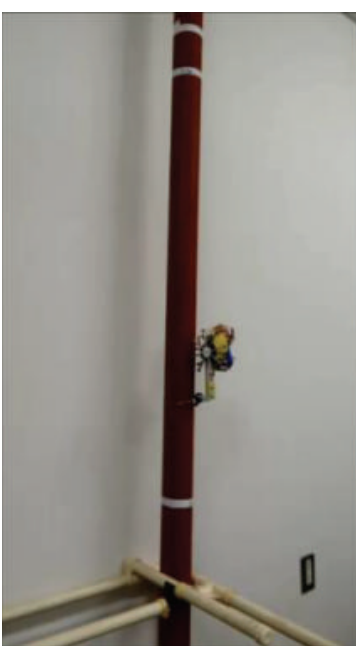

$4.0 \mathrm{~s}$

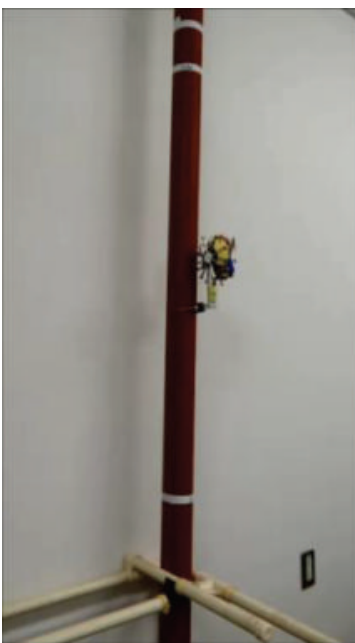

$6.0 \mathrm{~s}$

FIGURE 12: Robot moving vertically along a steel pipe.

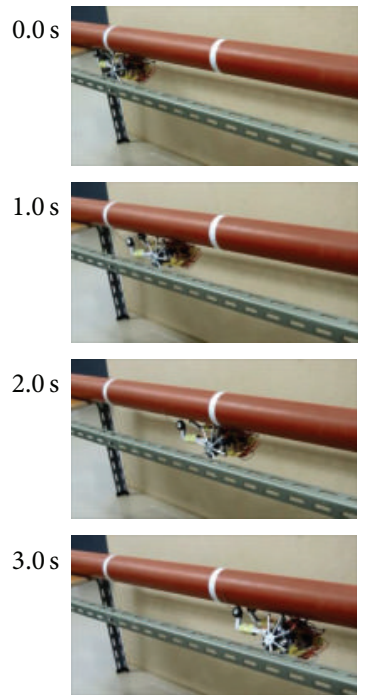

FIGURE 13: Robot moving horizontally along a steel pipe.

Figure 14 shows schematic diagrams of the attitude of the robot when moving horizontally and obliquely on the pipe. It can be seen that when the pipe is inclined, both the front and back wheels are in contact with the pipe, which makes it stable and unlikely to fall off. This is not the case when the pipe is horizontal, because the robot tilts about its front wheels, causing its rear wheels to lose contact with the pipe. The situation might be avoided by redesigning the robot so that its center of gravity is in front of its rimless wheels.

The robot occasionally fell from not only the horizontal pipe but also the inclined pipe. When the robot runs on the inclined pipe, it keeps its stability because the rear wheels touch the pipe. The robot fell from the pipe all of a sudden. This result suggests that the magnetic force of the robot is not enough to retain the robot to the steel pipe. To verify the hypothesis, we used a simulation model of the rimless wheel for the dynamic analysis of magnetic force. Figure 15 shows relationship between rotation angle and the magnetic force in the whole of a rimless wheel. The magnetic force in the entire wheel changes periodically whenever rotating by $45^{\circ}$ because the rimless wheel has eight magnets. Dynamic analysis result showed that the minimum attaching force of the rimless wheel is $1.69 \mathrm{~N}$. The weight of pipe inspection robot is $380 \mathrm{~g}$. When both of the right and left rimless wheels produce minimum attaching force, the attaching force is only $3.38 \mathrm{~N}$. Therefore, the robot would fall from the steel pipe. The cause of the robot falling depends on magnetic force shortage of the magnets. The permanent magnets should be exchanged for ones which can produce stronger attaching force. However, magnetic force must be as low as the motor can rotate. Further work is required to select magnets which produce the suitable force.

\section{Conclusions}

A prototype robot was developed for inspecting the outer surface of steel pipes. The robot is equipped with rimless wheels, to the spokes of which neodymium magnets are attached. It also has a link mechanism that allows the camber angle of its right and left wheels to be adjusted. Guides are attached to the rear of the robot so that it does not undergo yawing motion on the steel pipe. Experimental tests showed that it was capable of travelling along pipes with diameters of 60.5 to $101.6 \mathrm{~mm}$, although it fell from a pipe with a diameter of $21.7 \mathrm{~mm}$. However, it is thought to be likely that if the spokes are made longer, the robot would also be capable of travelling on such a narrow pipe. The magnetic force of the robot is not enough to retain the robot to the steel pipe. The permanent magnets should be exchanged for ones which can produce suitable attaching force. The movable load in the absence of slippage was $155 \mathrm{~g}$, which would allow it to carry a small camera to inspect pipes. Certain results were obtained in laboratory. Further experiments in actual environment are required. 

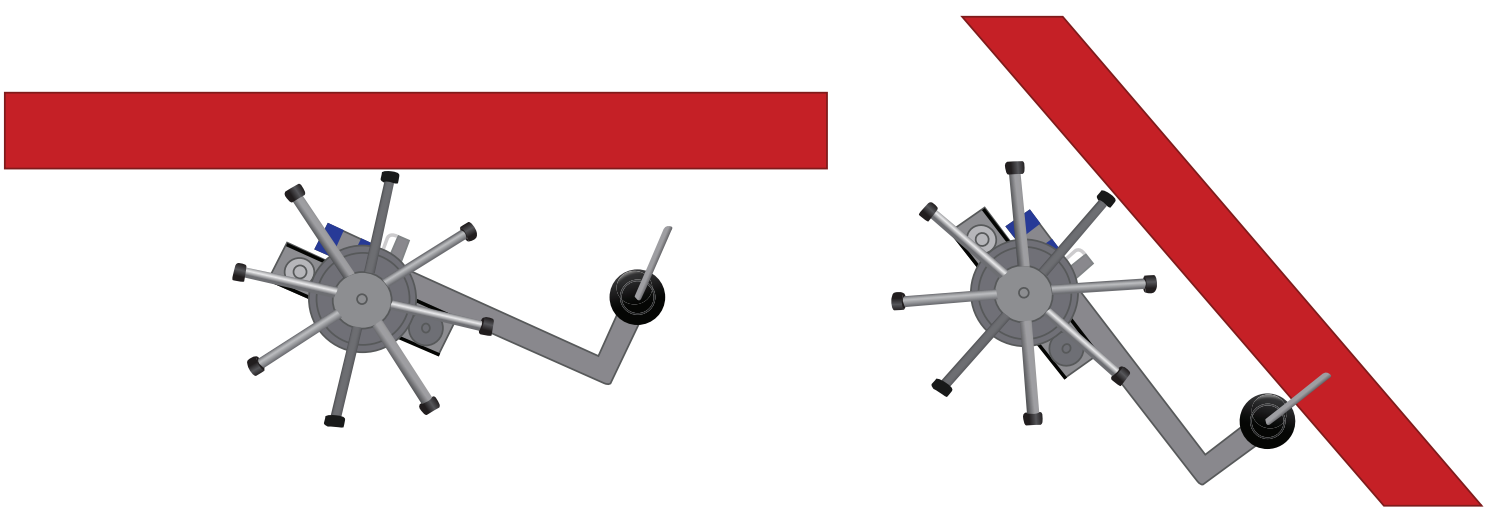

Figure 14: Attitude of robot on steel pipe.

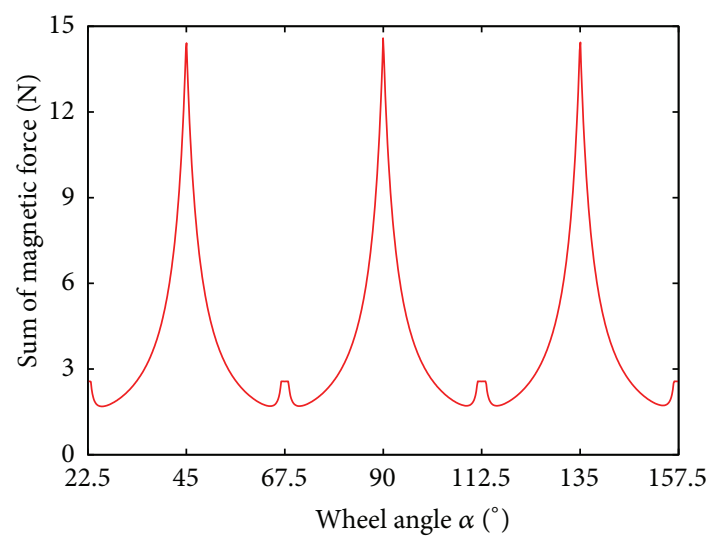

FIGURE 15: Relationship between rotation angle and the magnetic force of the whole of a rimless wheel.

If there are small obstacles on the pipe, the pipe inspection robot can stride them by rimless wheels. On the other hand, the robot cannot stride the large ones. We should stop the robot from crashing the obstacle. However, rear guides of the robot prevent it from changing the moving direction on the pipe. We will redesign the robot for practical use to change the moving direction.

\section{Conflict of Interests}

The authors declare that there is no conflict of interests.

\section{References}

[1] O. Tătar, D. Mândru, and I. Ardelean, "Development of mobile minirobots for in pipe inspection tasks," Mechanika, vol. 68, no. 6, pp. 60-64, 2007.

[2] D. Wu, H. Ogai, Y. Yeh, K. Hirai, T. Abe, and G. Sato, "Pipe inspection robot using a wireless communication system," Artificial Life and Robotics, vol. 14, no. 2, pp. 154-159, 2009.

[3] N. A. B. H. Yahya, N. Ashrafi, and A. H. Humod, "Development and adaptability of in-pipe inspection robots," IOSR Journal of Mechanical and Civil Engineering, vol. 11, no. 4, pp. 1-8, 2014.
[4] M. Horodinca, I. Doroftei, E. Mignon, and A. Preumont, "A simple architecture for in-pipe inspection robots," in Proceedings of the International Colloquium on Autonomous and Mobile Systems, Magdeburg, Germany, 2002.

[5] M. Hamada, M. Sasaki, K. Koizumi, T. Sasaki, and K. Kinosita, "Development of out-pipe robot," in Proceedings of the 43rd JSME Hokuriku-Shinetsu Branch Annual Meeting, 2006.

[6] H.-B. Yun, S.-H. Kim, L. Wu, and J.-J. Lee, "Development of inspection robots for bridge cables," The Scientific World Journal, vol. 2013, Article ID 967508, 17 pages, 2013.

[7] C. Choi, S. Jung, and S. Kim, "Feeder pipe inspection robot with an inch-worm mechanism using pneumatic actuators," International Journal of Control Automation and Systems, vol. 4, no. 1, pp. 87-95, 2006.

[8] T. Yukawa and H. Okano, "Development of a mechanism of pipe-surface inspection robot," Journal of the Japan Society for Precision Engineering, vol. 74, no. 6, 2008.

[9] M. F. Silva, R. S. Barbosa, and A. L. Oliveira, "Climbing robot for ferromagnetic surfaces with dynamic adjustment of the adhesion system," Journal of Robotics, vol. 2012, Article ID 906545, 16 pages, 2012.

[10] W. Shen, J. Gu, and Y. Shen, "Permanent magnetic system design for the wall-climbing robot," Applied Bionics and Biomechanics, vol. 3, no. 3, pp. 151-159, 2006.

[11] M. Kashinoki, Y. Takada, T. Kawai, and K. Koyama, "Running ability evaluation of bridge inspection robot with permanent magnets," in Proceedings of the 12th Symposium on Evaluation and Diagnosis, CD-ROM, 2013.

[12] Y. Takada, K. Kirimoto, T. Tajiri, and T. Kawai, "Development of a bridge inspection robot working in three-dimensional environment," Transactions of the Japan Society of Mechanical Engineers, vol. 79, no. 805, pp. 3135-3146, 2013. 

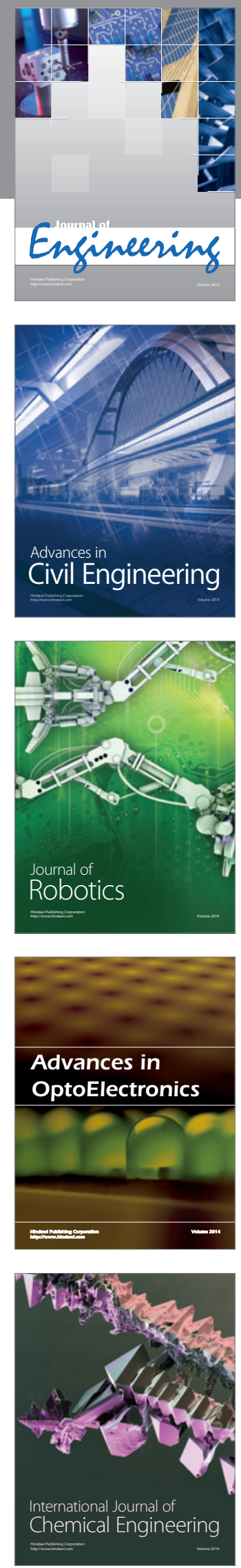

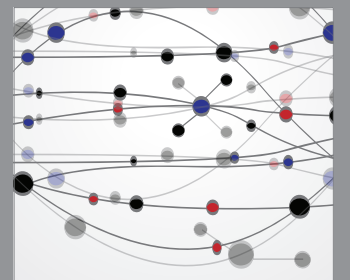

The Scientific World Journal
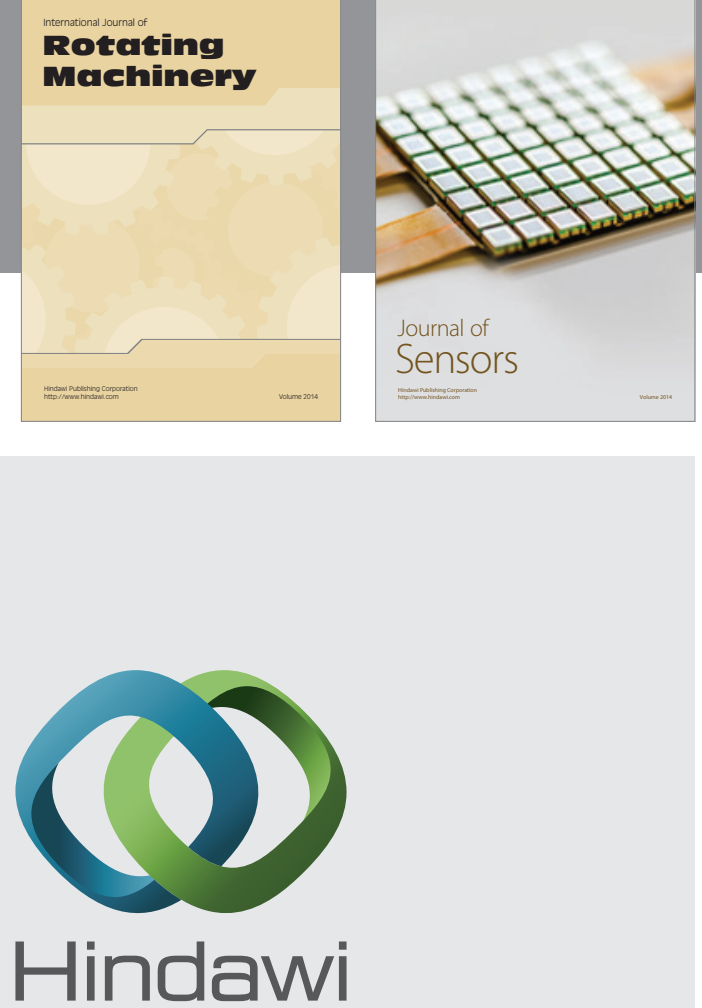

Submit your manuscripts at http://www.hindawi.com
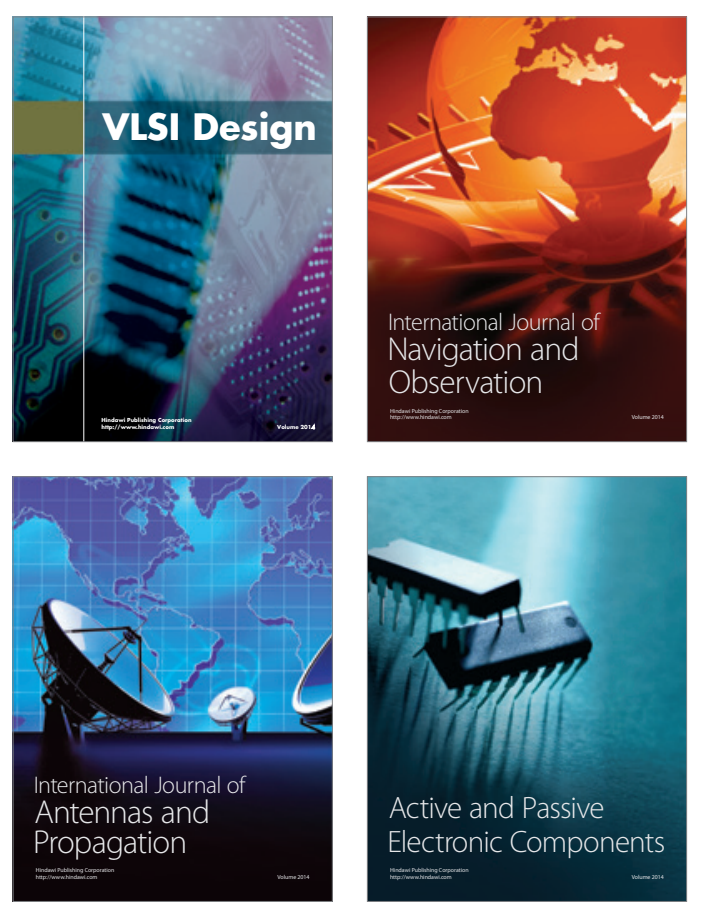
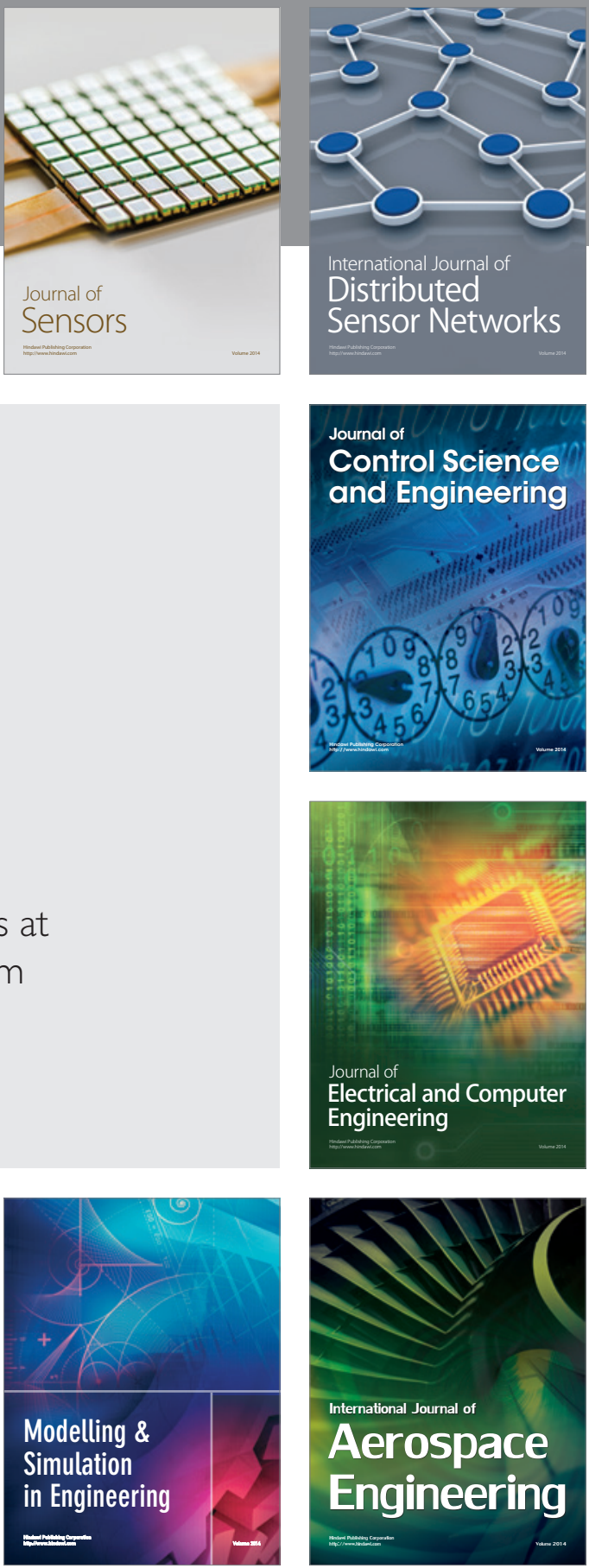

Journal of

Control Science

and Engineering
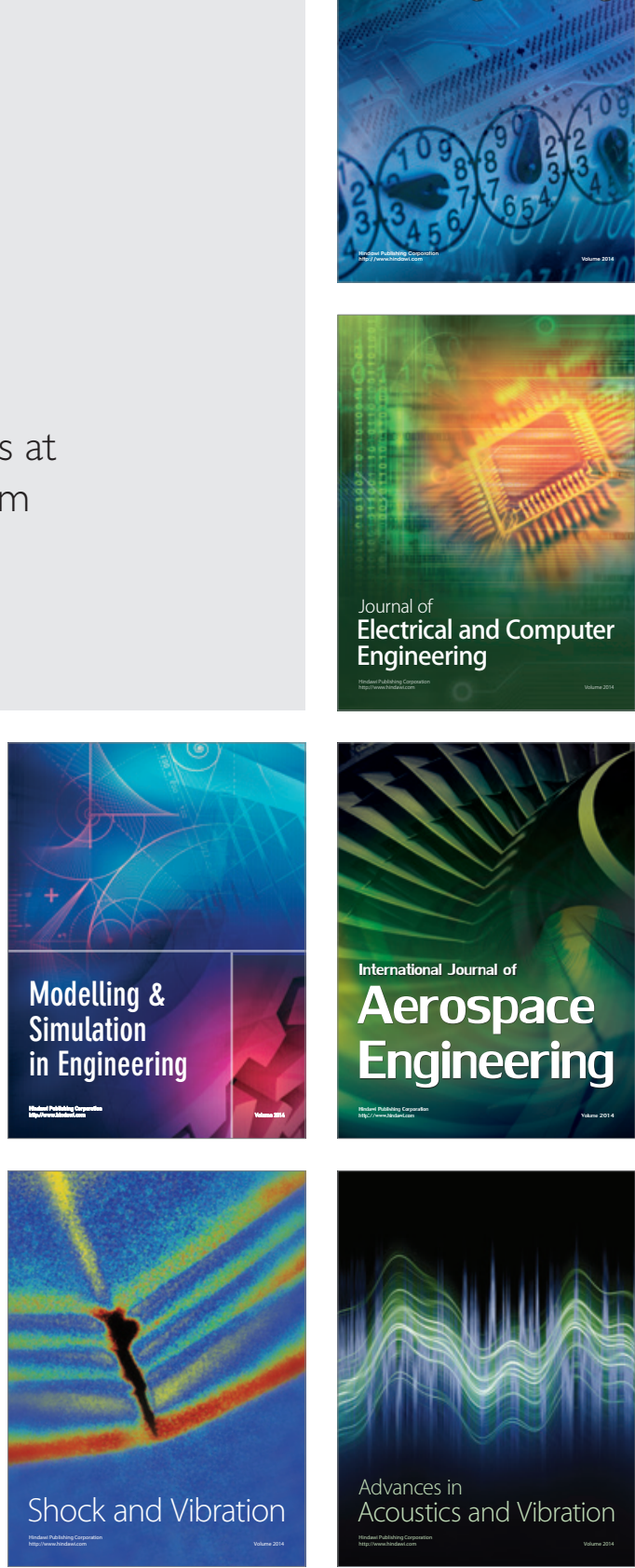